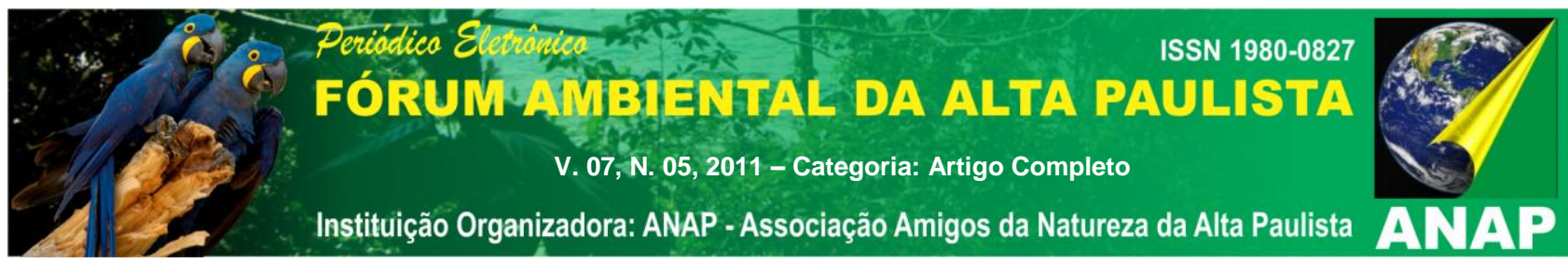

\title{
OS IMPACTOS AMBIENTAIS DECORRENTES DO PROGRAMAS DE REGULARIZAÇÃO FUNDIÁRIA SUSTENTÁVEL
}

\author{
Jeane Aparecida Rombi de Godoy Rosin ${ }^{1}$
}

RESUMO: O artigo proposto tem por objetivo desenvolver reflexões sobre a sustentabilidade de políticas públicas de regularização fundiária, tendo como base analítica a problemática socioambiental oriunda da ocupação do espaço urbano em APP - Área de Preservação Permanente. Nesse sentido, a análise empreendida teve como foco a questão dos processos informais de assentamentos humanos estabelecidos em APPs urbanas, por grupos sociais de menor renda ou sem renda, tendo como preocupação fundamental elucidar, durante todo o desenrolar da discussão, a complexa questão da informalidade, com a preocupação de trazer para o contexto da mesma, a verdadeira proporção dos impactos ambientais, da precariedade urbana e da vulnerabilidade, que tem, ao longo de décadas, afligido um universo crescente de vidas humanas. No contexto da problemática da efetividade das políticas públicas, gestão urbana e qualidade de vida, a discussao se volta para os fundamentos legais, técnicos e às questões vitais ao desenvolvimento da temática, relacionados às esferas: acadêmica, social, política e administrativa. Desse modo, o artigo estruturase, partindo de uma abordagem genérica, com o intuito de compreender o descompasso existente entre a formulação da política urbana e habitacional e as diversidades geográficas, sócio-culturais das áreas urbanas de cada localidade.

PALAVRAS CHAVE: Impactos ambientais; Sustentabilidade; Regularização Fundiaria.

\section{INTRODUÇÃO}

No decorrer das últimas décadas, o intenso processo de urbanização das cidades brasileira foi drasticamente marcado pela descontrolada ocupação informal de áreas de fragilidade ambiental, tais como: as áreas de preservação permanente,

\footnotetext{
${ }^{1}$ Arquiteta e Urbanista pela FAUT-SP, Especialista em Planejamento e Gestão Municipal pela UNESP - Campus de Presidente Prudente e Mestre em Direito pela UNIVEM - Centro Universitário de Marília. E-mail: jeanerosin@terra.com.br
} 
áreas de mananciais, áreas de encostas, áreas non-aedificandi, ou seja, áreas tuteladas pelo ordenamento jurídico em razão de seus valores ambientais. A ocorrência estrondosa dos processos de informalidade urbana, em áreas periféricas, assim como a intensa densificação dos assentamentos informais consolidados, é para alguns autores dentre eles, SMOLKA (2003, p.263), decorrentes não apenas do aumento absoluto e relativo de pobres urbanos, mas, sobretudo da "falta de programas habitacionais, da queda de investimentos públicos em equipamentos urbanos e serviços e do próprio esvaziamento do planejamento urbano", sem contar que "todos esses são fatores que, em última análise, incidem diretamente na oferta do solo urbanizado". Nesse sentido, é de fundamental importância considerar que, o acesso ao mercado regular de terras esta diretamente vinculado ao poder de aquisição ou de compra da população, o que vem esclarecer o motivo pelo qual, milhares de famílias de menor poder aquisitivo, são circunstancialmente obrigadas a ocuparem de modo irregular áreas públicas ou privadas, muitas destas, impróprias à ocupação humana. Em síntese, conforme exposição realizada ao longo desta discussão, os processos de ocupações informais podem ser entendidos como resultados dos ciclos econômicos manifestados drasticamente no processo de produção das cidades, caracterizadas acentuadamente pela concentração de renda, assim como pela omissão do Estado.

A partir deste contexto, os assentamentos informais localizados em áreas ambientalmente vulneráveis, passaram a se constituir num aspecto que vai muito além da delicada problemática urbana, tendo em vista a complexidade das questões de ordem jurídica, social, econômica, cultural, e principalmente urbanística, decorrentes da longa e vergonhosa ausência do Estado frente à questão. Todavia, em razão da dimensão e da gravidade com que essas tipologias aparecem nos cenários urbanos, tendo em vista, que parte considerável delas são instaladas em espaços legalmente protegidos, a questão que envolve os processos de regularização fundiária em APPs urbanas, tem de modo contundente, não apenas pautado os atuais debates nos mais diversos meios, como também, causado o 
despertar do Estado para o cumprimento de suas responsabilidades constitucionais relacionadas à efetivação do Direito à Cidade.

\section{IMPACTOS AMBIENTAIS URBANOS}

O direito urbanístico positivado pelo ordenamento jurídico brasileiro busca alcançar o debate social em torno das tensões dialéticas da produção do espaço urbano, considerando as questões de ordem econômica e a apropriação dos recursos ambientais, com a finalidade da melhoria na qualidade de vida.

É incontestável que os efeitos decorrentes das transformações ambientais atingem direta ou indiretamente a todos, essencialmente aqueles que habitam as áreas urbanizadas. Nesse sentido, a intensificação das questões ambientais, sobretudo nas cidades, tem reafirmado a vinculação existente entre a degradação do espaço natural e a conseqüente degradação da qualidade de vida, assim como à vulnerabilidade de comunidades a inúmeros riscos. Daí emerge o dever primordial de manutenção da vida, enquanto um dever ético, levando a um processo de reflexão mais aprofundada dos padrões de apropriação da natureza pelo homem, que segundo Leff (2001, p.295) "significa pensar o habitar como projeto transformador do meio, como processo de apropriação social das condições de habitabilidade do planeta". No âmbito da questão, a tutela da vida significa também, a tutela da vida nas cidades, que segundo Fittipaldi (2006, p.56) "compreendem, ao mesmo tempo, meio ambiente natural, construído e cultural, sendo o local adequado para a tutela do meio ambiente como um todo, e da realização do direito à cidade, direito humano, fundamental e metaindividual."

Reconhecer assim, a importância da construção histórica das dimensões dos direitos fundamentais ${ }^{2}$ possibilitou uma leitura apropriada dos parâmetros de

\footnotetext{
${ }^{2}$ Ensina-nos Carlos Alberto M. de QUEIROZ (2004) que os direitos fundamentais da pessoa humana são aqueles que todas as pessoas devem ter, em todo lugar e a qualquer tempo, e cuja privação causaria uma grave ofensa à justiça. $E$, esses direitos apresentam-se como direitos fundamentais de primeira, segunda, terceira e quarta gerações: 1. Os diretos fundamentais de primeira geração, ou direitos de liberdade, são aqueles que têm por titulares o indivíduo. [...]; 2. Os direitos fundamentais de segunda geração são os direitos econômicos, sociais e culturais que dominaram o século XX.
} 


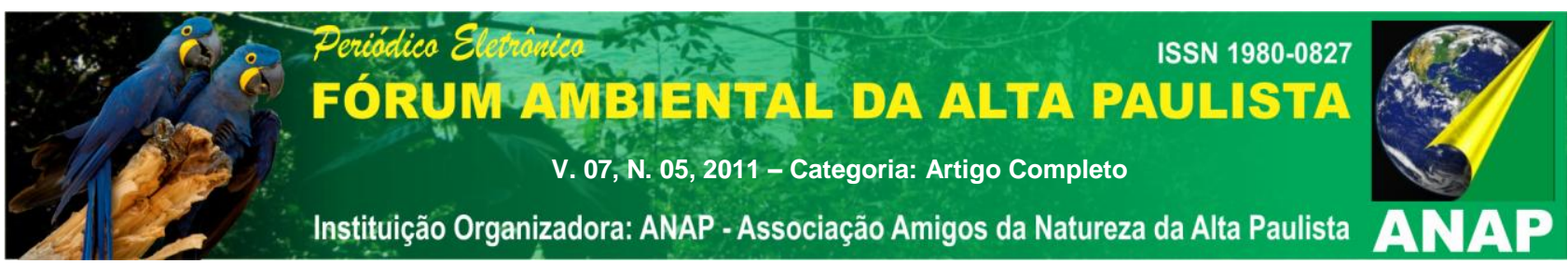

proteção jurídica do meio ambiente, pois segundo Padilha (2010, p.36) "o meio ambiente é a grande expressão dos denominados "direitos de terceira dimensão", os direitos característicos da "fraternidade".

Nesse processo, tornou-se fundamental a incorporação da tutela ao meio ambiente nos textos constitucionais mais recentes, sobretudo após a realização e notória influência da Declaração de Princípios de Estocolmo ${ }^{3}$ ocorrida de 05 a 16 de junho de 1972 na Suécia, ainda que de forma gradativa, em razão de se constituir num documento sem força vinculante. Entretanto, conforme destaca Padilha (2010, p.61) ao citar Chris Wolf "a Declaração de Estocolmo propiciou a primeira moldura conceitual abrangente para a formulação e implementação estruturada do Direito Internacional do Meio Ambiente". Porém, foi somente após a realização da Conferência das Nações Unidas sobre Meio Ambiente e Desenvolvimento no Rio de Janeiro (CNUMAD) - a RIO-92, ou ainda a Cúpula da Terra, que o meio ambiente passou a ser tratado como valor fundamental, passando a influenciar a construção da normatividade ambiental em nível global, na perspectiva de ser um direito positivado em constituições de diversos países.

O conceito de impacto ambiental foi definido no artigo $1^{\circ}$ da Resolução nํ 001/86 do Conselho Nacional do Meio Ambiente (CONAMA ${ }^{4}$ ), ao determinar que,

Nasceram juntamente com o princípio da igualdade, dominando, por completo, as Constituições do segundo pós-guerra; 3. Os direitos fundamentais de terceira geração são os direitos da fraternidade, segundo Karel VASAK, que os identificou em número de cinco - direito ao desenvolvimento, direito da paz, direito ao meio ambiente, o direito de propriedade sobre o patrimônio comum da humanidade e, finalmente, o direito de comunicação; 4. Os direitos fundamentais de quarta geração são os direitos de solidariedade, que são 0 direito à democracia, 0 direito à informação e o direito ao pluralismo, sendo que deles dependem a concretização da sociedade aberta ao futuro. Disponível em: juridico.com.br/site/index.php?n link=revista artigos leitura\&artigo id=1057>. Acesso em: 25 janeiro 2011.

${ }^{3}$ A Declaração de Estocolmo é um documento elaborado durante a Conferência das Nações Unidas sobre Meio Ambiente realizada de 05 a 16 de junho de 1972 em Estocolmo, Suécia, este foi o primeiro documento da história de um direito ambiental internacional, que reconheceu o direito de manter um ambiente saudável e natural. Disponível em: < http://www.dforceblog.com/pt/declaracaode-estocolmo/>. Acesso em: 5 fevereiro 2011.

${ }^{4}$ A Resolução Conama 001/86 de 23.01.86 "estabelece as definições, as responsabilidades, os critérios básicos e as diretrizes gerais para uso e implementação da Avaliação de Impacto Ambiental como um dos instrumentos da Política Nacional do Meio Ambiente". Disponível em: <http://www.cati.sp.gov.br/Cati/_servicos/dcaa/legislacao_ambiental/Resolu\%C3\%A7\%C3\%A30\%20C ONAMA\%20001_1986\%20- 


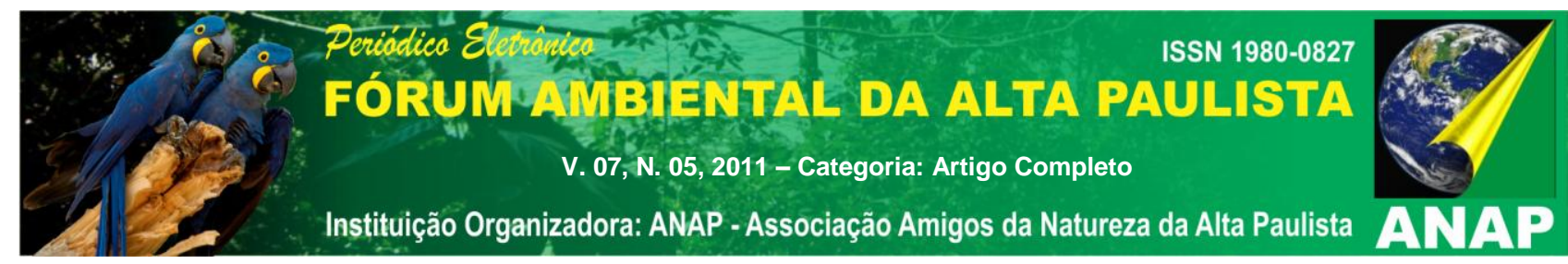

Artigo $1^{\circ}$ - Para efeito desta Resolução, considera-se impacto ambiental qualquer alteração das propriedades físicas, químicas e biológicas do meio ambiente, causada por qualquer forma de matéria ou energia resultante das atividades humanas que, direta ou indiretamente, afetam:

I - a saúde, a segurança e o bem-estar da população;

II - as atividades sociais e econômicas;

III - a biota;

IV - as condições estéticas e sanitárias do meio ambiente;

$\mathrm{V}$ - a qualidade dos recursos ambientais.

A partir deste conceito e considerando a autonomia dos entes da federação, cabe à municipalidade determinar regras, ou seja, leis, que possam regular os conflitos socioambientais presente nos aglomerados urbanos, principalmente aqueles referentes aos impactos ambientais urbanos, onde segundo Coelho (2005, p.21) é "produto e processo de transformações dinâmicas e recíprocas da natureza e da sociedade estruturada em classes sociais", com esta preocupação o referido autor alerta que,

[...] os estudos convencionais de impactos ambientais urbanos limitaram-se a associar crescimento urbano com as características ecológicas e renunciam à compreensão da cidade moderna (e as mudanças nas formas de produção, funções, estruturas dinâmicas infra-estruturais e significados arquitetônicos) (COELHO, 2005, p.35).

Frente a esses apontamentos, Coelho (2005) complementa, salientando que é possível identificar outros impactos ambientais relacionados com:

a) políticas públicas cristalizadoras de desigualdades sociais;

b) realidade social em suas diversas dimensões; e

c)forças sociais (locais e globais) que influenciam a (re) estruturação socioespacial, interna à cidade e externa, abrangendo um espaço regional mais amplo (COELHO, 2005, p.35-36).

Neste mesmo enfoque, Rogers (2001, p.18) esclarece que o crescimento veloz das cidades as transforma em "estruturas complexas e difíceis de administrar"

\%20com\%20altera\%C3\%A7\%C3\%A30\%20Res\%20CONAMA\%20011_1986.pdf>. Acesso em: 25 Abril 2011. 


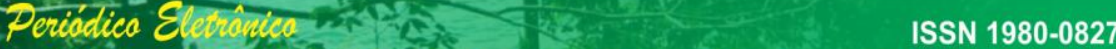

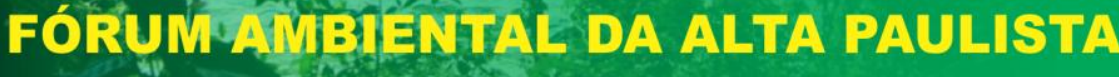 \\ V. 07, N. 05, 2011 - Categoria: Artigo Completo \\ Instituição Organizadora: ANAP - Associação Amigos da Natureza da Alta Paulista}

tornando difícil lembrar "que elas existem em primeiro lugar, e acima de tudo, para satisfazer as necessidades humanas e sociais das comunidades". Acselrad (1999, p.18) complementa afirmando que "o futuro das cidades dependerá em grande parte dos conceitos constituintes do projeto de futuro construído pelos agentes relevantes na produção do espaço urbano".

Segundo Ferreira (2003), o ambiente urbano ou as cidades possuem um papel essencial para o equilíbrio ecológico dos demais ambientes, uma vez que, quando esses espaços se encontram em desarmonia, o que se vê é o comprometimento da infraestrutura, seguido da degradação da paisagem do local. Deste modo, torna-se necessário o monitoramento do crescimento urbano, para que haja uma distribuição eqüitativa dos investimentos em infraestrutura e democratização do acesso aos serviços urbanos, combatendo as desigualdades sócio-espaciais.

Nessa perspectiva, pode-se falar de uma visão ideológica de justiça socioambiental partilhada no ambiente urbano, que segundo Lynch (2001) é fruto das preocupações com 0 meio ambiente, considerando a relação homem $\mathrm{x}$ natureza, onde se

[...] redesenhar a distribuição espacial e social de fatores ambientais positivos e negativos, partilhar as responsabilidades inevitavelmente associadas com a proteção ambiental e, talvez o mais importante, definir os loci de tomada de decisão ambiental (LYNCH, 2001, p.57).

Neste contexto, Teixeira (2006, p.21) lembra que um dos maiores desafios da humanidade é de "conciliar o desenvolvimento com a proteção e a preservação ambiental, para não inviabilizar a qualidade de vida das futuras gerações, da coletividade e o exercício de propriedade sobre os bens ambientais."

Swyngedouw (2001, p.84) considera que a cidade, a sociedade e a natureza, são representações "inseparáveis, mutuamente integradas, infinitamente ligadas e simultâneas, responsáveis pelas "contradições, tensões e conflitos". Segundo Braga (2003) essa nova conjuntura apresentada por Swyngedouw (2001), 


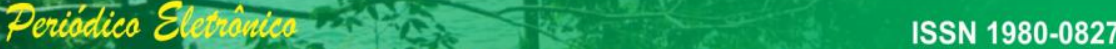

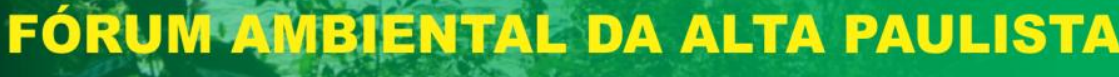 \\ V. 07, N. 05, 2011 - Categoria: Artigo Completo \\ Instituição Organizadora: ANAP - Associação Amigos da Natureza da Alta Paulista}

faz parte da dinâmica das cidades, como por exemplo, os conflitos sócio-ambientais oriundos do parcelamento do solo urbano.

[...] o avanço da urbanização sobre o meio natural, de maneira desordenada, tem causado a degradação progressivas das áreas de mananciais remanescentes, com a implantação de loteamentos irregulares e a instalação de usos e índices de ocupação incompatíveis com a capacidade de suporte do meio. O parcelamento indiscriminado do solo nas periferias urbanas é uma das principais fontes de problemas ambientais das cidades (BRAGA, 2003, p.113).

Segundo Braga (2003, p.114-115) essas ocupações em áreas de mananciais são apenas parte do problema, pois as "alterações decorrentes do uso do solo, como a retirada da vegetação [...] e a impermeabilização do solo [...], causam um dos impactos humanos mais significativos no ciclo hidrológico", como por exemplo, os problemas de drenagem urbana.

A ocupação e o uso do solo urbano de forma desordenada criaram espaços com os mais diversos problemas ambientais e, entre tais situações, a drenagem da água pluvial está presente em quase todas as cidades brasileiras.

$\mathrm{Na}$ realidade, muitos desses eventos são decorrentes do processo de ocupação irregular em regiões de alta vulnerabilidade ambiental. Em grande parte das situações, os próprios ocupantes ao modificarem as condições físicas do local, seja nos morros ou nas várzeas, buscando eliminar as "inadequações naturais" acabam por realizar uma ocupação predatória, que tem, ao longo dos anos, contribuído para a ocorrência de acidentes de diversas ordens, tais como os deslizamentos de encostas, as enchentes e inundações.

A ocorrência desses eventos, além de gerar vultosas somas em perdas materiais, é responsável, todos os anos, por perdas humanas de valores incalculáveis.

A partir da compreensão de que a incidência dos desastres se dá em grande parte, em razão da existência da vulnerabilidade das áreas de risco, onde os fenômenos são únicos e por sua vez, produzem conseqüências diversificadas, já que as áreas atingidas possuem não apenas, contextos geográficos diferenciados, mas também políticos, econômicos, sociais, culturais, dentre outros. 


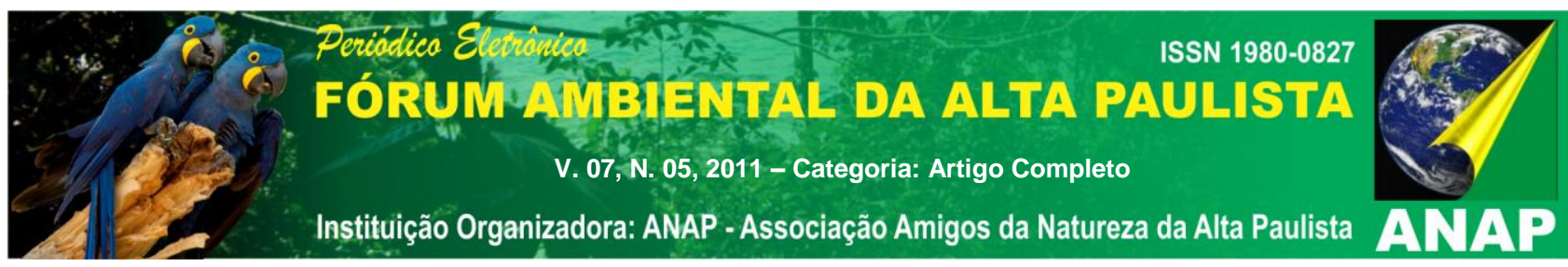

Nesse contexto, conforme informações do Ministério da Saúde (2002), a ocorrência dos desastres ambientais em áreas urbanas pode afligir de modo contundente a saúde pública por inúmeros fatores, como:

a) Causar um número inesperado de mortes, ferimentos ou enfermidades, que podem exceder a capacidade de resposta dos serviços locais de saúde;

b) Afetar os recursos humanos de saúde comprometendo o funcionamento da estrutura local de saúde;

c) Danificar ou destruir a infra-estrutura de saúde local e equipamentos podendo alterar a prestação de serviços de rotina e ações preventivas, com graves conseqüências no curto, médio e longo prazo, em termos de morbi-mortalidade;

d) Destruir ou interromper os sistemas de produção e distribuição de água, bem como dos serviços de drenagem, limpeza urbana e esgotamento sanitário, favorecendo ocorrência e proliferação de doenças.

e) Destruir ou interromper os serviços básicos como telecomunicações, energia, represas, subestações e meios de transportes, aeroportos, rodovias, oleodutos e gasodutos, entre outras.

f) Provocar desastres secundários que podem destruir ou danificar instalações e fontes fixas (plantas industriais, depósitos de substâncias químicas, comércio de agro-químicos, armazenamento em área rural) ou móveis (transporte), ocasionando rompimentos de dutos ou lagoas de contenção de rejeitos, vazamentos de substâncias químicas ou radioativa, oferecendo riscos à saúde humana.

g) Contaminação microbiológica devido a alagamentos de lixões e aterros sanitários.

h) Aumenta o risco de enfermidades psicológicas na população afetada.

i) Provocar a dissolução de comunidades e famílias geradas pela migração, desemprego, perda do patrimônio e mortes de familiares.

j) Causar escassez de alimentos, provocando a redução do consumo e trazer graves conseqüências nutricionais, nos casos de desastres prolongados;

k) Provocar movimentos populacionais, em busca de alimentos, fontes alternativas de água, emprego, entre outros, podendo acarretar riscos epidemiológicos.

I) Aumentar a vulnerabilidade das pessoas devido a uma maior exposição às condições climáticas (MINISTERO DA SAÚDE, 2002, p.9).

Gráfico 02 - Tipos de desastres naturais ocorridos no Brasil (1900-2006) demonstra que os tipos de desastres mais freqüentes foram as inundações, com $59 \%$ dos registros, seguidas pelos escorregamentos (14\%).

Gráfico 02 - Tipos de desastres naturais ocorridos no Brasil (1900-2006).

Legenda: IN - Inundação, ES - Escorregamento, TE - Tempestades, SE - Seca, TX - Temperatura Extrema, IF - Incêndio Florestal e TR - Terremoto. 

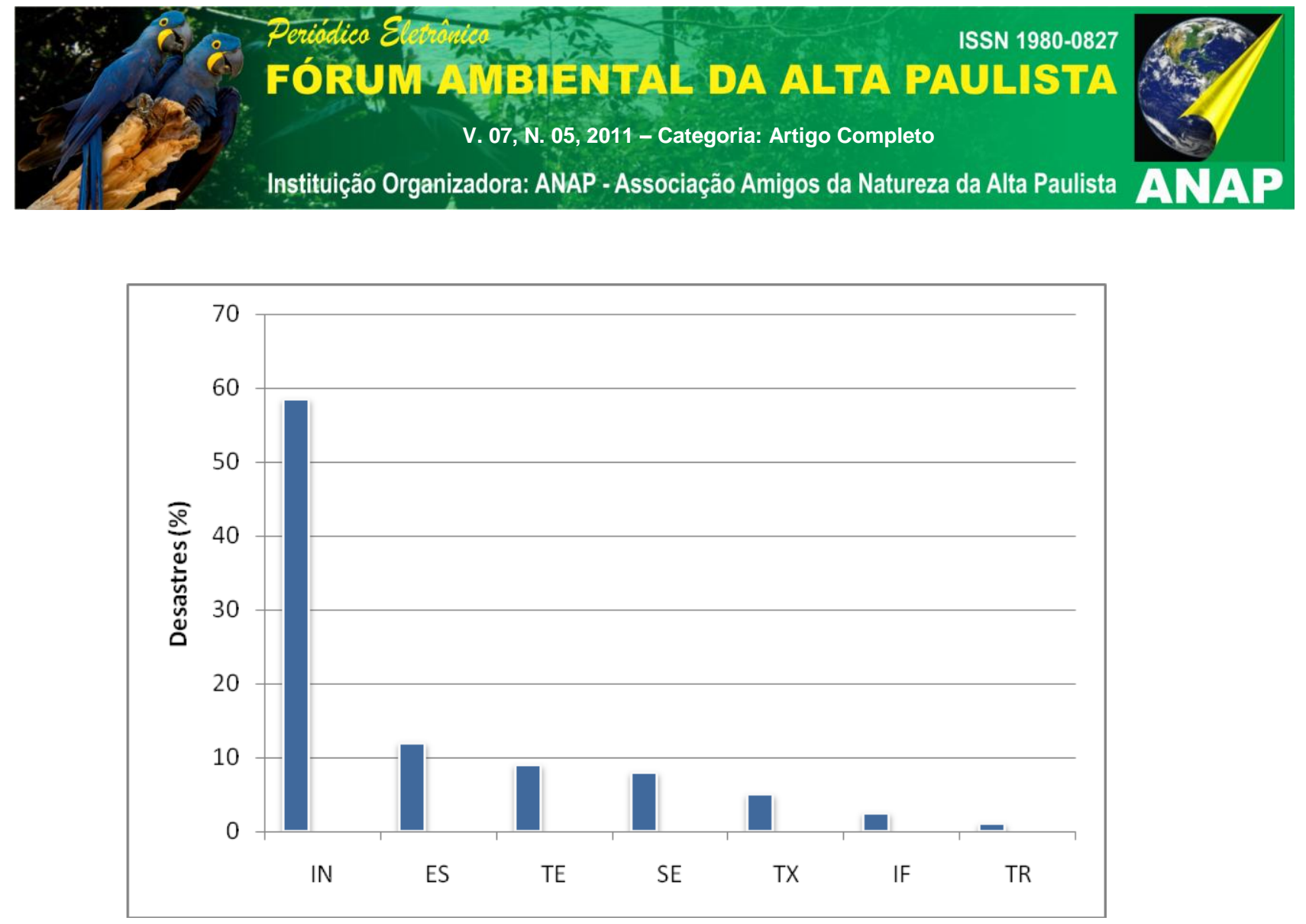

Fonte: MARCELINO, 2008, p.17. - Adaptado pela Autora

Desse modo, devido à freqüência com que têm ocorrido os eventos desta natureza, muitos estudos referentes à questão afirmam que os mesmos, além de estarem fortemente vinculados às condições geomorfológicas da área de incidência, não podem deixar de considerar suas relações com a vulnerabilidade social dos segmentos de menor poder aquisitivo, principalmente aqueles residentes em assentamentos precários, via de regra, localizados em áreas de risco. Neste cenário, a vulnerabilidade social está associada a todos os aspectos decorrentes da pobreza, que apesar de suas dimensões, tem permanecido por anos invisíveis aos olhos do Estado e da sociedade, que passam a percebê-las somente em momentos de tragédia, como os de catástrofes.

A pesquisa de Informações Básicas Municipais - MUNIC, elaborada em 2002 e editada somente em 2005, possibilitou uma visão bastante significativa referente à ocorrência de fenômenos ou desastres naturais no Brasil. Este estudo fez dois apontamentos importantes: o primeiro mostrou que no país os maiores eventos registrados estão associados a inundações, escorregamentos e erosão; o segundo evidenciou que esses processos estão intensamente relacionados aos processos de 


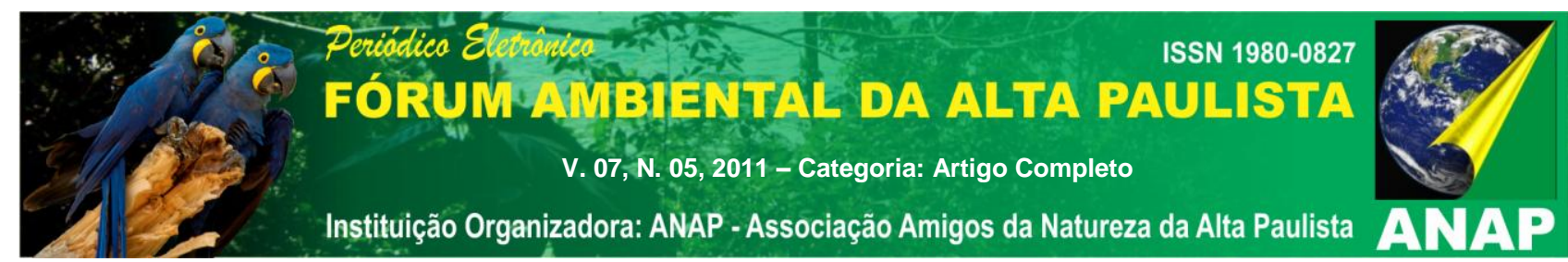

degradação de áreas ambientalmente vulneráveis, derivadas do processo de informalidade urbana.

Os dados revelaram que cerca de $50 \%$ dos municípios brasileiros declararam ter sofrido algum tipo de alteração ambiental nos 24 meses anteriores a pesquisa e, dentre estes, cerca de $16 \%$ sofreram com deslizamento de encosta e $19 \%$ com inundações. Outro fenômeno enfocado é a alteração da paisagem causada pela erosão do solo, resultando em voçorocas, ravinas e deslizamentos (capitulo $\mathrm{V}$ ). Os dados da pesquisa mostraram também que, dos municípios que sofrem com deslizamento de terra, $25 \%$ associam esse fenômeno a degradação de áreas protegidas e a ocupação irregular de áreas frágeis, outros $34 \%$ atribuíram como causa o desmatamento. No caso dos municípios com problemas de inundação, aproximadamente $25 \%$ atribuíram o fato a degradação de áreas protegidas e a ocupação irregular de áreas frágeis e $30 \%$ ao desmatamento. Em síntese, de acordo com as informações obtidas pela MUNIC, processos como deslizamento de encostas, inundações e erosão estão fortemente associados à degradação de áreas frágeis, potencializada pelo desmatamento e ocupação irregular (MAFFRA; MAZZOLA, 2007, p.10).

A cidade apresenta uma dinâmica geomorfológica própria, à medida que o espaço urbano é modificado, há um impacto direto no contexto espacial, criando uma nova dinâmica para as inter-relações urbanas, como por exemplo, o surgimento de áreas de alagamentos e inundação.

\section{SUSTENTABILIDADE URBANA}

Considerando a complexidade da qualidade ambiental urbana, Rogers (2001, p.155) esclarece que a sustentabilidade no ambiente urbano deve emergir como "uma nova ordem de eficiência econômica, beneficiando a todos os cidadãos, em vez de beneficiar alguns poucos em detrimento de muitos". Neste enfoque, a noção da sustentabilidade urbana surge como forma de conjugação da questão econômica, social, política, cultural e ambiental, onde haja o comprometimento com processos de urbanização e práticas urbanísticas que incorporem a dimensão socioambiental na produção e na gestão do espaço. 


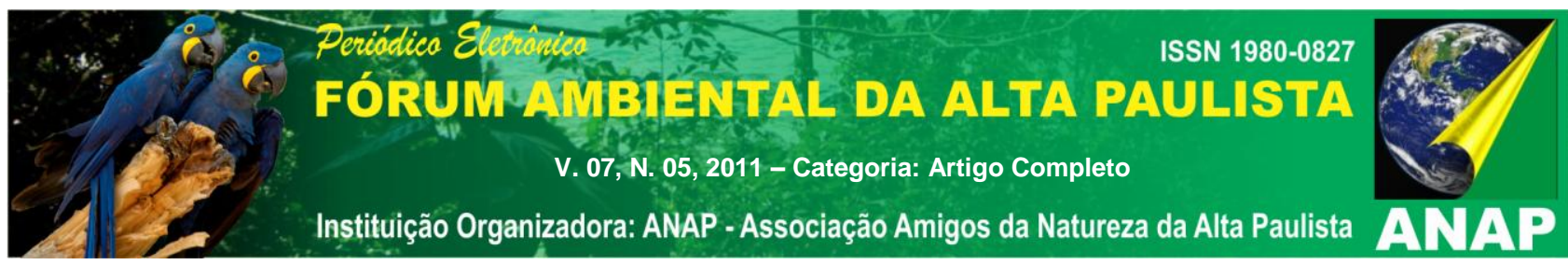

Segundo Saule Junior (1997, p.61), a sustentabilidade urbana passa a ser alicerçada nas "funções sociais da cidade" específicas, de caráter "difuso", onde devem oferecer mecanismos institucionais, administrativos e jurídicos que possam promover a "redução das desigualdades sociais, promoção da justiça social e melhoria da qualidade de vida urbana", promovendo o acesso à "moradia, transporte público, saneamento, cultura, lazer, segurança, educação, saúde".

Segundo Rodriguez (2001, p.99), o termo sustentabilidade defendido pela CMMAD pode ser compreendido a partir da

[...] gestão e administração dos recursos e serviços e orientação das mudanças tecnológicas e institucionais, no sentido de assegurar e alcançar a contínua satisfação das necessidades humanas para as gerações presentes e futuras, dentro dos limites da capacidade de sustentação dos sistemas ambientais (RODRIGUEZ, 2001, p.99).

O princípio da sustentabilidade contempla a necessidade de um ambiente equilibrado, mediante a fatores sociais, políticos, econômicos, ambientais, de modo a assegurar a qualidade de vida em cidades. Por quanto, o cenário das cidades se apresenta heterogêneo, marcado por processos de desigualdades sociais, que se cristalizam na segregação socioespacial, assim como, pela privação dos serviços públicos a boa parte da população, a qual particularmente, a que se encontra em assentamentos precários, a exemplo das favelas, onde os espaços são constituídos por um amontoado de construções precárias ao longo dos becos estreitos, desprovidos das condições mínimas de habitabilidade.

Para Acselrad (1999) a sustentabilidade urbana está estritamente relacionada com a qualidade de gestão urbana, considerando os pólos distintos:

[...] de um lado, aquele que privilegia uma representação técnica das cidades pela articulação da noção de sustentabilidade urbana aos modos de gestão dos fluxos de energia e materiais associados ao crescimento urbano; de outro, aquele que define a insustentabilidade das cidades pela queda da produtividade dos investimentos urbanos, ou seja, pela incapacidade destes últimos acompanharem o ritmo de crescimento das demandas sociais, 0 que coloca em jogo, o espaço urbano como território político (ACSELRAD, 1999, p.79). 


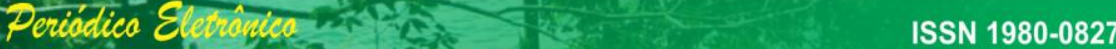

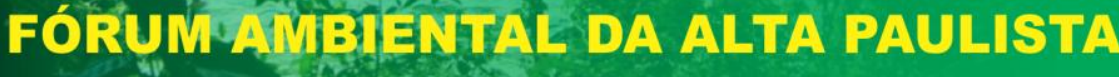 \\ V. 07, N. 05, 2011 - Categoria: Artigo Completo \\ Instituição Organizadora: ANAP - Associação Amigos da Natureza da Alta Paulista}

Para equacionar estes pólos e viabilizar a sustentabilidade urbana, parte-se do pressuposto da necessidade da aplicação de instrumentos jurídicos para disciplinar a ocupação e uso do solo urbano, considerando a inter-relação entre dimensões sociais, econômicas e ambientais para a realização de uma gestão eficiente, que seja capaz de promover a construção de uma sociedade justa, eqüitativa e democrática.

Neste contexto, o planejamento e a gestão das áreas urbanas devem, além de adotar medidas e técnicas para a adequação física de seus espaços, adotar essencialmente técnicas e instrumentos que promovam a convivência social, de maneira que os desiguais tenham suas diferenças amenizadas pela árdua busca de implementar espaços cada vez mais democráticos de vivência saudável, o que em outras palavras significa, a luta por uma melhoria na qualidade de vida.

Esta linha de pensamento também encontra respaldo nas colocações de Struchel (2006).

Desse modo, nos resta refletir que, não obstante a falsa aparência de segregação das discussões das agendas urbanas e ambientais seja em nível municipal ou regional, fato é que, quando tratamos das questões relacionadas à gestão da cidade, temos necessariamente de compatibilizar e homogeneizar as discussões de modo a convergir em único fim: a qualidade de vidas nas cidades (STRUCHEL, 2006, p.284).

Nesta abordagem, Rosetto (2003, p.36) evidencia que, "nas questões urbanas, a complexidade das estruturas sociais, econômicas e ambientais transforma a busca pelo desenvolvimento sustentável em tarefa das mais difíceis". A indissociabilidade da problemática social urbana e da problemática ambiental das cidades "exige que se combinem dinâmicas de promoção social com dinâmica de redução dos impactos ambientais no espaço urbano". Entretanto, não se ignora a diferença entre as agendas, principalmente ao conteúdo relacionado ao desenvolvimento socioeconômico, tanto dos países centrais ou de países de economia periférica, uma vez que a grande discussão evidenciada diz respeito à implementação do desenvolvimento sustentável em áreas urbanas. 


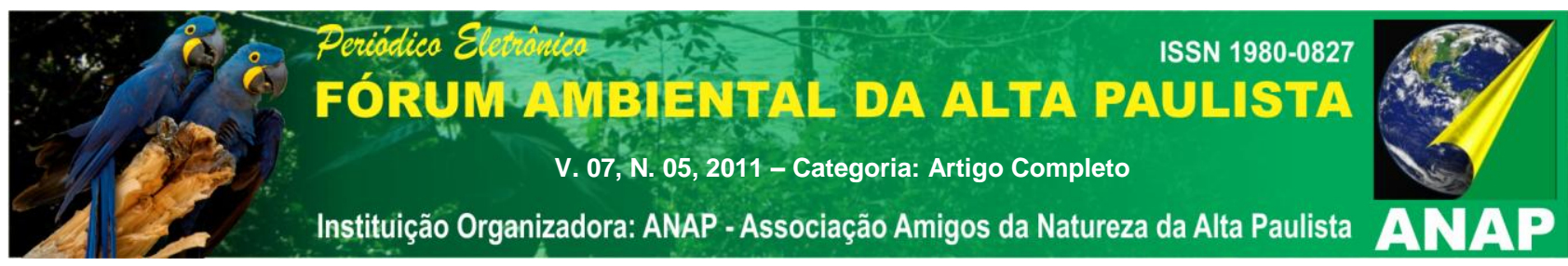

Acselrad (2001, p.45) ensina que nas leis a "idéia de sustentabilidade é assim aplicada às condições de reprodução da legitimidade das políticas urbanas". A elaboração de políticas públicas que privilegiam o desenvolvimento sustentável da cidade não pode ignorar que existe "uma forma social durável de apropriação e uso do meio ambiente dada pela própria natureza das formações biofísicas", isto é, que existe uma "diversidade de formas sociais de duração dos elementos da base material do desenvolvimento." (ACSELRAD, 1999 apud COELHO, 2005, p.39).

Segundo Braga (2003, p.119-120), o Estatuto da Cidade oferece vários instrumentos urbanísticos e jurídicos para que a municipalidade possa "evitar e corrigir os efeitos negativos do crescimento urbano sobre o meio ambiente", de modo que a "ordenação do uso do solo" evite a "deterioração das áreas urbanizadas e a poluição e degradação ambiental, e a expansão urbana".

Considerando o recorte dado para foco desta pesquisa, o Estatuto da Cidade prevê como um dos instrumentos da política de desenvolvimento urbano, o zoneamento ambiental, no qual os cursos d'água, as encostas, as áreas de fragilidade ambiental, devem ser encaradas como "recursos e a cidade deve ser entendida como uma natureza antrópica, na qual as leis naturais não estão revogadas." (CARVALHO, 2003, p.25).

Todavia, o zoneamento é o instrumento de planejamento urbano mais difundido no Brasil e sua prática tem tido caráter fundamentalmente econômico, muito mais afeito às vicissitudes do mercado imobiliário, do que aos problemas socioambientais das cidades. Segundo Braga (2003, p.121) é imprescindível que as leis de zoneamento urbano contemplem "diretrizes de proteção e controle ambiental", com o fim de "controlar o uso e a ocupação de fundos de vale, das áreas sujeitas à inundação, das cabeceiras de drenagem, das áreas de alta declividade e a promover o aumento da permeabilidade do solo urbano".

O Estatuto da Cidade define o direito à cidades sustentáveis, como o direito à terra urbana, à moradia, ao saneamento ambiental, à infra-estrutura urbana, ao transporte e aos serviços públicos, ao trabalho e ao lazer, para as presentes e futuras gerações, e a gestão democrática por meio da participação da população e de associações representativas dos vários segmentos da comunidade na formulação, execução e acompanhamento de 


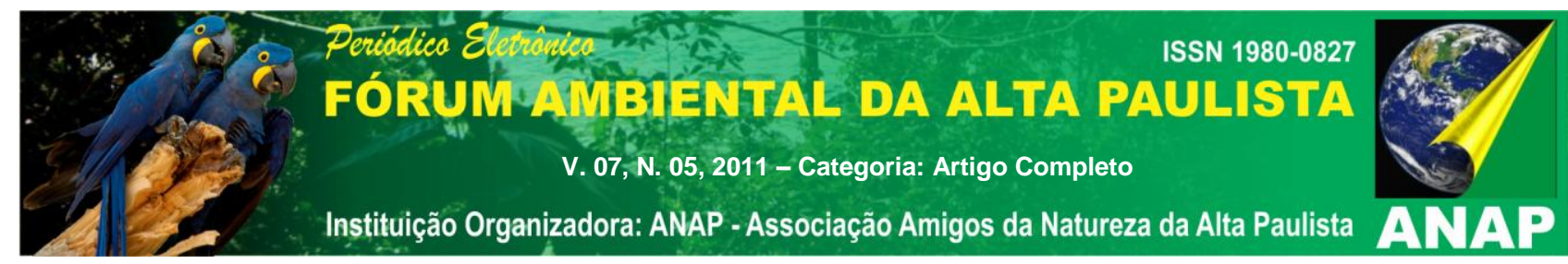

planos, programas e projetos de desenvolvimento urbano (SAULE JÚNIOR et al., 2009, p.259).

Deste modo, o Estatuto da Cidade além de apresentar a natureza jurídica da cidade sustentável, é um instrumento jurídico que contempla normas de ordem pública e interesse social, que tem como objetivo tutelar matéria de ordem urbanística em prol do bem coletivo e do equilíbrio ambiental. Assim, pode-se afirmar que o Estatuto da Cidade é o principal instrumento jurídico para promoção de uma sustentabilidade urbana, equacionando a função social da cidade com a qualidade ambiental urbana.

\section{REGULARIZAÇÃO FUNDIÁRIA SUSTENTÁVEL}

O processo de urbanização das cidades no país, tanto aqueles relativo às cidades de médio e grande porte, intensificou os processos de diferenciação socioespacial. Dessa forma, o estudo desse fenômeno, tem mostrado ao longo dos anos, que o acelerado processo de urbanização brasileiro se constituiu num dos fatores responsáveis pela profunda crise urbana, assinalada por um misto de segregação socioespacial, alto déficit habitacional, degradação ambiental como também o acentuado acesso informal à terra urbana que vem assolando de modo contundente as cidades brasileiras. A conseqüência desse tipo de crescimento demográfico, aliada às restrições econômicas ocorridas nestas últimas décadas, tem se revelado como tendência peculiar da anárquica urbanização brasileira, a qual contribuiu para a conseqüente queda da qualidade de vida urbana. Este processo está associado à degradação ambiental, que afeta mais fortemente os extratos sociais de menor renda, ou seja, as populações mais carentes estão assentadas em áreas desprovidas de infraestrutura e também estão, freqüentemente, em espaços urbanos de alto risco sujeito a enchentes, deslizamentos e processos erosivos.

Diante destes cenários, a legislação brasileira, tem-se preocupado em criar mecanismos voltados para o desafio de alcançar a reversão dos mesmos. Desse modo, no atual momento, têm-se despontado novos caminhos de atuação para o 


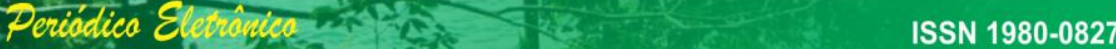

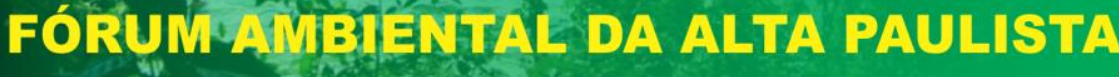 \\ V. 07, N. 05, 2011 - Categoria: Artigo Completo \\ Instituição Organizadora: ANAP - Associação Amigos da Natureza da Alta Paulista}

enfrentamento da questão, iniciado pela nova abordagem resultante da evolução conceitual do termo de Regularização Fundiária e, principalmente pela adoção de novos mecanismos para trabalhar com a delicada problemática.

Com este enfoque, a regularização fundiária sustentável contemplada pelo artigo 9ำ da Resolução CONAMA 369/2006 é antes de tudo, um mecanismo legal, por meio do qual se torna possível a legalização de parcelas da cidade informal, bem como, abre precedente jurídico para inocentar administradores públicos da omissão, ora de descaso e irresponsabilidade diante da necessidade do ordenamento do solo urbano.

Entretanto, um dos maiores equívocos da regularização fundiária sustentável é que:

- apesar de ter sua efetividade em áreas localizadas "exclusivamente nas faixas de APP" (inciso IV, artigo 9², Resolução CONAMA 369/2006), não atende as demandas socioambientais presentes nas APP urbanas, pois ao invés de combater a pobreza, tem-se na sua aplicabilidade a consolidação das mazelas urbanas;

- retrocede na previsão legal do inciso III, do artigo $4^{\circ}$ da Lei no 6.766/79 , ao determinar que deva "ser respeitada faixas mínimas de 15 metros para cursos de água de até 50 metros de largura" (alínea "a", inciso IV, artigo 9º, Resolução CONAMA 369/2006);

- prevê a possibilidade de diminuição maior desta área com processo

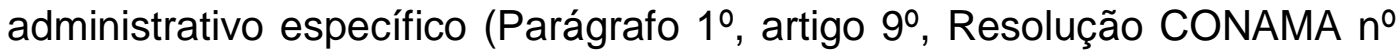
369/2006);

- nessas áreas, consideradas de inundação, quando inseridas no tecido urbano, ainda como uma das diferentes tipologias de APPs, via de regra são ocupadas por população de menor poder aquisitivo;

- retrata a omissão e o descaso dos administradores públicos diante não apenas dos impactos ambientais dos diversos sistemas que são de vital importância para o equilíbrio do meio urbano, tais como, o de

\footnotetext{
5 “III - ao longo das águas correntes e dormentes e das faixas de domínio público das rodovias e ferrovias, será obrigatória a reserva de uma faixa não-edificável de 15 (quinze) metros de cada lado, salvo maiores exigências da legislação específica;" (Artigo 4ํㅜ da Lei ํㅡ 6.766/79)
} 
abastecimento de água, o de manutenção do lençol freático, o sistema de drenagem urbana;

- amplia possibilidades de riscos oferecidas nestas localidades, relacionadas à ocorrência de acidentes ambientais, onde além do registro das perdas materiais incontáveis, tem-se registrado o crescente aumento, não apenas do número de mortes imediatas, como também um número que permanece oculto ainda, de pessoas que têm seu estado de saúde comprometido em função das diversas doenças transmitidas durante a ocorrência desses eventos.

Não se pode ignorar que, importantes ações já foram implementadas em várias regiões do País, com a preocupação de promover a regularização dos assentamentos ilegais e melhorias urbanísticas, entretanto os resultados obtidos estão longe de atender a crescente demanda de informalidade que caracterizam estas ocupações. Na realidade, o contexto apresentado evidencia, que a questão da regularização está apenas começando e que há um árduo caminho a ser percorrido, tendo em vista o balanço insatisfatório apresentado por esses programas até o momento no país. A partir desse contexto, a regularização fundiária torna-se uma questão fundamental tanto no desenvolvimento como para a efetivação da Política Urbana Nacional. Foi com esse propósito, com base no Estatuto da Cidade, que foi formatado o Programa Minha Casa Minha Vida (PMMV) regulamentando por meio da lei federal no 11.977/2009, a regularização fundiária sustentável, com o intuito de assegurar acesso à moradia digna e à cidade formal para os grupos sociais de menor renda - estes foram os pressupostos que pautaram sua formatação, entretanto sua fase de implementação tenha-se revelado práticas contraditórias e incoerentes com esse discurso. Porém, não se pode deixar de considerar a relevância da aprovação desses dois novos diplomas jurídicos para o fortalecimento dos desafios referentes ao enfrentamento dos processos de informalidade urbana. Assim, torna-se também importante ressaltar que os programas de regularização fundiária, enquanto instrumento fundamental da política de desenvolvimento urbano, se constituem antes de tudo, ainda que tardiamente, 
em alternativas criadas pelo estado, não apenas para a definição de uma ordem urbanística que se deseja inclusiva, mas como condição sine qua non de combate aos processos cíclicos de informalidade urbana. Em síntese, a questão urbana no Brasil permaneceu por muito tempo abandonada a própria sorte, proporcionando o aumento vertiginoso de demandas nas mais diversas áreas, que inegavelmente se cristalizam em tipologias disformes e vulneráveis a todo tipo de riscos. Frente aos efeitos decorrentes desse processo, tem-se o despertar do Estado, que tem procurado agir por meio de políticas publicas, que ate o momento não tem conseguido produzir resultados satisfatórios. Em face da exposição apresentada, pode-se depreender, que não se trata apenas de prover moradia, é imprescindível que o novo desenho de políticas públicas de desenvolvimento urbano incorpore de modo imperativo a definição de ações visando o alcance do pleno direito à qualidade de vida, não se limitando ou satisfazendo em oferecer de modo vexatório a possibilidade de sobrevivência àqueles que ao longo de décadas sequer conseguiram um local para morar. Assim, é de fundamental importância, que tanto as políticas publicas voltadas para a questão urbana sejam integradas à um projeto de desenvolvimento da nação, concebido em essência com coragem de romper padrões e força o suficiente para inaugurar um nova era - a era de um planejamento alicerçado por mecanismos inovadores não somente com capacidade propositiva mas sobretudo com instrumentos de gestão aptos a realizar a tão sonhada reforma urbana.

\section{CONSIDERAÇÕES FINAIS}

As demandas sociais e ambientais presentes nas cidades brasileiras não podem mais ser toleradas, nem pela ordem urbanística e muito menos pela ordem jurídica, pois os dados apresentados em diversas pesquisas elaboradas por orgãos governamentais e entidades acadêmicas apontam que as famílias de baixa ou sem renda são as mais numerosas, desprovidas e desassistidas em suas necessidades 


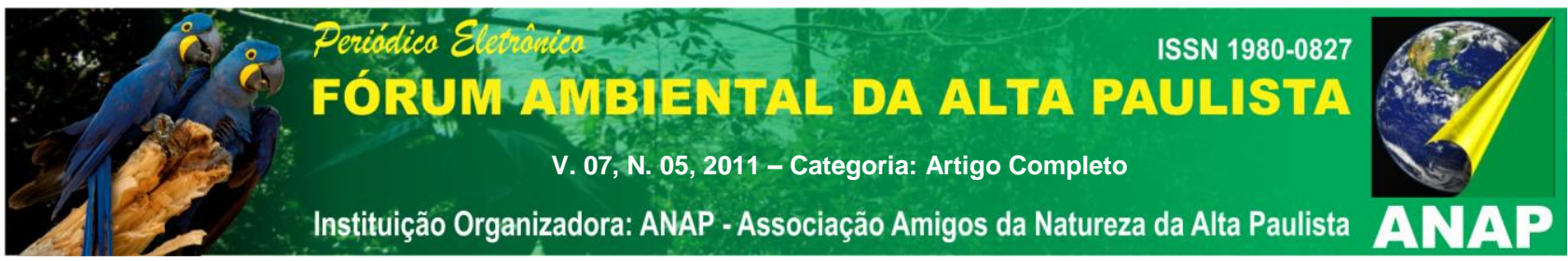

mais elementares, o que torna evidente que esses programas deveriam necessariamente procurar responder à essas demandas, ou seja a dos grupos economicamente desfavorecidos. Frente a esse contexto, torna-se mister que a formatação das políticas públicas em qualquer setor, deva visar primordialmente o atendimento das necessidades primeiras do cidadão em situação de vulnerabilidade, e nao serem pautadas exclusivamente pelo interesse de grupos hegemônicos, os quais tem dominado ao longo dos anos o arranjo político e econômico do país, causando de modo indireto o comprometimendo da realização de um desenvolvimento em bases justas e democráticas.

\section{REFERÊNCIAS}

ACSELRAD, Henri. Discursos da Sustentabilidade Urbana. Revista Brasileira de Estudos Urbanos e Regionais, Campinas: no 01, maio/ 1999.

ACSELRAD, Henri. Sentidos da sustentabilidade urbana. In: ACSELRAD, Henri (Org.). A duração das cidades: sustentabilidade e risco nas políticas urbanas. Rio de Janeiro: DP\&A, 2001. p. 27-55.

BRAGA, Roberto. Planejamento urbano e recursos hídricos. In: BRAGA, R.; CARVALHO, P. F. C. (Org.). Recursos Hídricos e Planejamento Urbano e Regional. Rio Claro: Laboratório de Planejamento Municipal - Deplan - UNESP - IGCE, 2003. p. 113 - 127.

CARVALHO, Pompeu Figueiredo de Carvalho. Águas nas cidades: reflexões sobre usos e abusos para aprender novos usos. In: BRAGA, R.; CARVALHO, P. F. C. (Org.). Recursos Hídricos e Planejamento Urbano e Regional. Rio Claro: Laboratório de Planejamento Municipal - Deplan - UNESP - IGCE, 2003. p. 9 - 36.

COELHO, Maria Célia Nunes. Impactos Ambientais em Áreas Urbanas - Teorias, Conceitos e Métodos de Pesquisa. In: GUERRA, A. J. T.; CUNHA, S. B. (org). Impactos Ambientais Urbanos no Brasil, 3르 ed. Rio de Janeiro: Bertrand Brasil, 2005.

FERREIRA, Ângela Maria Rodrigues. Turismo e Sustentabilidade. In: Turismo, cultura identidade, José Clerton de Oliveira Martins (org.). São Paulo: Roca, 2003.

FITTIPALDI, Mariana. Direito à Cidade: diálogo de equidade entre o direito à moradia e o direito ao meio ambiente. Dissertação (Mestrado) Programa de Pós-Graduação em Direito - Departamento de Direito. Pontifícia Universidade Católica do Rio de Janeiro - Rio de Janeiro, 2006. $247 \mathrm{f}$. 

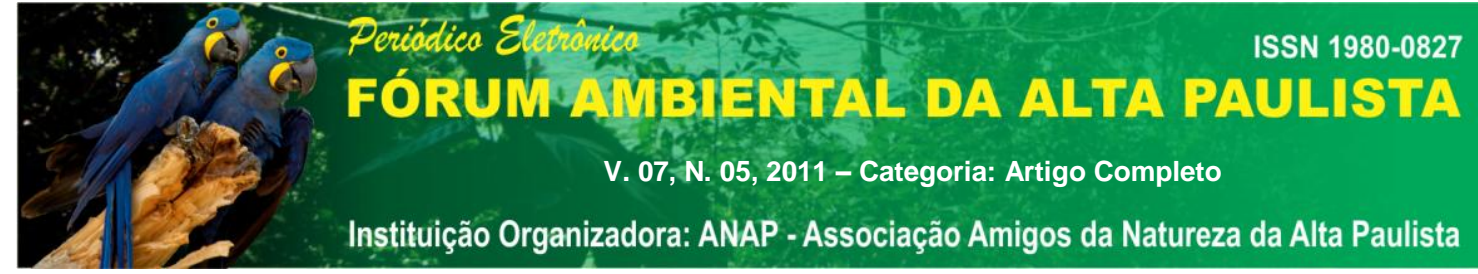

LEFF, E. Saber Ambiental: sustentabildiade, racionalidade, complexidade, poder. Petrópolis: Vozes, 2ed, 2001.

LYNCH, Bárbara Deutsch. Instituições internacionais para a proteção ambiental: suas implicações para a justiça ambiental em cidades latino-americanas. In: ACSELRAD, Henri (Org.). A duração das cidades: sustentabilidade e risco nas políticas urbanas. Rio de Janeiro: DP\&A, 2001. p. 57-82.

MAFFRA, Cristina Q.T.; MAZOLLA, Marcelo. As razões dos desastres em território brasileiro. In: SANTOS, Rozely Ferreira dos (Org.) Vulnerabilidade Ambiental: desastres naturais ou fenômenos induzidos?. 1르 ed. Brasília: Ministério do Meio Ambiente, 2007.

MARCELINO, Emerson Vieira. Desastres Naturais e Geoteconologias: Conceitos Básicos. Santa Maria: INPE/CRS, 2008.

MINISTÉRIO DA SAÚDE. SECRETARIA DE VIGILÂNCIA EM SAÚDE. COORDENAÇÃO GERAL DE VIGILÂNCIA EM SAÚDE AMBIENTAL. Programa nacional de vigilância em saúde Ambiental dos riscos decorrentes dos desastres naturais - vigidesastres. Brasília/DF, 2002.

PADILHA, Norma Sueli. Fundamentos Constitucionais do Direito Ambiental Brasileiro. Rio de Janeiro: Elsevier, 2010. 452 p.

RODRIGUEZ, J. M. M. Desenvolvimento sustentável: níveis conceituais e modelos. In: RODRIGUEZ, J. M. M. \& SILVA, E. V. da. Desenvolvimento Local Sustentável. Fortaleza: Universidade Federal do Ceará, 2001.

ROGERS, Richard. Cidades para Um Pequeno Planeta. Tradução de Anita Regina Di Marco, 4를ㄷão. Barcelona: Editorial Gustavo Gili, 2001.

ROSSETTO, Adriana Marques. Proposta de um sistema integrado de gestão do ambiente urbano (SIGAU) para o desenvolvimento sustentável das cidades, Florianópolis, 2003. Tese (Doutorado em Engenharia da Produção) Universidade Federal de Santa Catarina. Programa de Pós-Graduação em Engenharia de Produção e Sistemas.

SAULE JUNIOR, Nelson. Novas perspectivas do direito urbanístico brasileiro. Ordenamento constitucional da política urbana: aplicação e eficácia do plano diretor. Porto Alegre: Sérgio Fabris Editor, 1997.

SAULE JÚNIOR, Nelson. O Direito à Cidade e a Revisão da Lei de Parcelamento do Solo Urbano. In: Nelson Saule Júnior et al. (org). Anais... V Congresso Brasileiro de Direito Urbanístico - Manaus 2008: O Direito Urbanístico nos 20 anos da Constituição Brasileira de 1988 - Balanço e Perspectivas. Porto Alegre: Magister, 2009.

SMOLKA, Martim O. Regularização da ocupação do solo urbano: a solução que é parte do problema que é parte da solução. In: FERNANDES, E.; ALFONSIN, B. M. (coord.). A lei e a ilegalidade na produção do espaço urbano. Belo Horizonte: Del Rey, 2003. p. 255-294. 


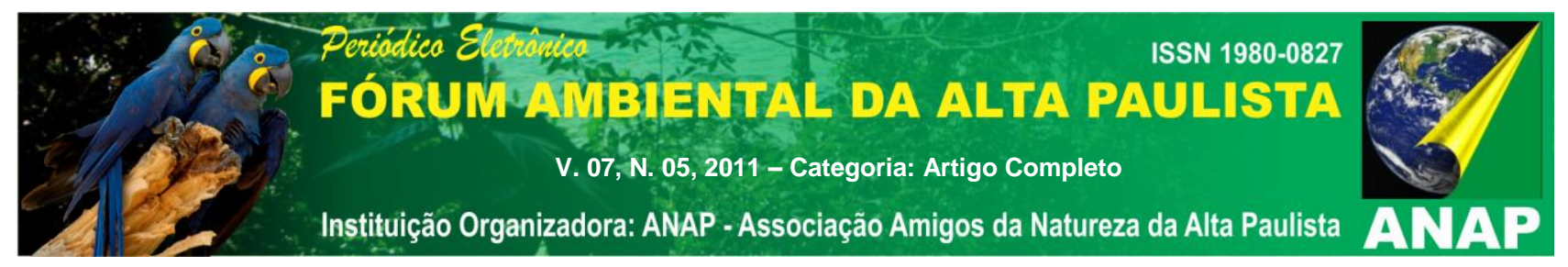

STRUCHEL, Andrea. A agenda urbano-ambiental para o município de Campinas. In: Fernandes, E., ALFONSIN, B. (coord). Direito Urbanístico: estudos brasileiros e internacionais. Belo Horizonte: Del Rey, 2006.

SWYNGEDOUW, Erik. A cidade como um híbrido: natureza, sociedade e "urbanizaçãocyborg". In: ACSELRAD, Henri (Org.). A duração das cidades: sustentabilidade e risco nas políticas urbanas. Rio de Janeiro: DP\&A, 2001. p. 83-104.

TEIXEIRA, Orci Paulino Bretanha. O Direito ao Meio Ambiente ecologicamente equilibrado como direito fundamental. Porto Alegre: Livraria do Advogado Ed., 2006. 